\title{
Aspectos Morfológicos da Junção Escamo-Colunar de Ratas em Estro Permanente e Tratadas com Associação de Estrogênio e Glicocorticóide
}

\author{
Morphological Aspects of the Squamocolumnar Junction of Rats in Permanent Estrus \\ Treated with an Association of Estrogen and Glucocorticoid
}

Flávia Cilene Maciel da Cruz ${ }^{1}$, José Maria Soares Júnior ${ }^{2}$, Rejane Mosquette ${ }^{1}$, Edmund Chada Baracat ${ }^{2}$, Manuel de Jesus Simões ${ }^{1}$

\begin{abstract}
RESUM0
Objetivo: avaliar o efeito da associação de dexametasona com estrogênio sobre a junção escamo-colunar (JEC) de ratas em estro permanente e ovariectomizadas (OvX).

Métodos: trinta ratas foram divididas em seis grupos com cinco animais cada: GEF-em estro fisiológico, tendo recebido propilenoglicol (veiculo); GOVX - em estro fisiológico com ovariectomia e tratadas com o veículo; GEP - em estro permanente (EP); GEPOVX - em EP, Ovx e tratadas com veículo; GESTR - em EP, Ovx e tratadas com $10 \mathrm{mg} /$ dia de benzoato de estradiol e GDEXAR - em EP, Ovx e tratadas com $10 \mathrm{mg} /$ dia de benzoato de estradiol e 0,8 $\mathrm{mg} /$ dia de dexametasona. O EP foi induzido com 1,25 mg/ animal de propionato de testosterona logo após o nascimento. Após 90 dias, as ratas foram ovariectomizadas nos grupos GOVX, GEPOVX, GESTR e GDEXAR. Após 21 dias de castração, os animais foram tratados por cinco dias consecutivos. No final do experimento, todos os animais foram sacrificados e o útero removido para rotina histológica.

Resultados: a JEC do GEP tinha limites irregulares e pouco nítidos, com vários brotamentos em direção da lâmina própria, bem como redução do número de leucócitos comparado a GEF. A JEC do GOVX e do GEPOVX se mostrou pouco nítida, com epitélio cúbico na parte endometrial e diminuição das camadas do epitélio escamoso, com atrofia estromal. No GESTR, a JEC apresentou-se bem mais desenvolvida que nos grupos GOVX e GEPOVX, mas assemelhando-se mais ao GEP devido aos limites pouco nítidos e aumento dos brotamentos. Já no GDEXAR, a JEC foi bem delimitada, se aproximando do aspecto do GEF.

Conclusão: nossos dados sugerem que a dexametasona associada ao estrogênio seria importante na restauração da morfologia normal da JEC em ratas que foram previamente induzidas a estro permanente e subseqüentemente submetidas a castração.
\end{abstract}

PALAVRAS-CHAVE: Histologia cervical. Junção escamo-colunar. Estrogênio.

\section{Introdução}

Em mulheres, o colo uterino é recoberto no seu canal por epitélio cilíndrico de origem mülleriana e na região externa por epitélio escamoso (estratificado) que tem origem no seio urogenital. A região de união desses dois tipos de

${ }^{1}$ Departamento de Morfologia e ${ }^{2}$ Departamento de Ginecologia da Universidade Federal de São Paulo (UNIFESP/EPM) Correspondência:

José Maria Soares Júnior

Rua Dr. Borges Lagoa, 512, apto. 152C

04038-000 - São Paulo - SP

e-mail: baracat.gineco@epm.br epitélio se chama junção escamo-colunar (JEC) e sua localização pode ser no orifício cervical externo, canal endocervical ou ectocervical (ectopia), conforme a idade da mulher, níveis séricos dos esteróides sexuais ou uso de medicamentos hormonais ${ }^{1}$.

Estudos clínicos mostram que há influência hormonal no processo de proliferação do epitélio endocervical, podendo-se deslocar a região da JEC para a região ectocervical. Já a diminuição dos niveis hormonais na pós-menopausa pode ocasionar efeito inverso ${ }^{2,3}$. Deve-se ressaltar que o conhecimento dos efeitos hormonais sobre o epitélio cervical ainda é limitado, principalmente nos 
casos de anovulação crônica com produção aumentada de androgênios, como ocorre nas pacientes com a sindrome dos ovários policísticos. Assim, há necessidade de estudos experimentais em animais para melhor compreensão.

O modelo de estudo em roedores é muito útil, visto que o comportamento do epitélio e do estroma cervical desses animais em face de esteróides sexuais é semelhante ao humano ${ }^{4}$.

Alguns aspectos histológicos do colo uterino das ratas durante o ciclo estral (ovulatório) devem ser citados. Datta et al. (1968) $)^{5}$ relataram que o colo uterino de ratas, na fase de estro e de metaestro (após ovulação), é revestido na sua porção mais externa por um epitélio estratificado pavimentoso queratinizado, sendo no diestro e proestro (antes e durante a ovulação) não queratinizado. Já Valente e Sasso (1992) ${ }^{6}$, estudando o colo uterino de ratas, observaram que a proporção de fibras colágenas e a infiltração de eosinófilos na lâmina própria eram maiores na fase de estro (após pico hormonal de estrogênio e progesterona) em comparação à de diestro (elevação hormonal). Ramos et al. (2002) ${ }^{7}$ referem que os aspectos morfológicos observados no colo uterino de ratas estão diretamente relacionados aos niveis de receptores de estrógeno e de progesterona.

A androgenização em ratas recém-nascidas acarreta anovulação crônica e também proliferação e cornificação acentuadas do epitélio escamoso cérvico-vaginal. Após a ovariectomia, esse processo regride, mas a atrofia epitelial é menos evidente do que nas ratas controle que tinham o ciclo estral normal ${ }^{8}$. Além disto, a resposta epitelial ao tratamento hormonal com estrogênio e progestagênio nos animais previamente androgenizados e ovariectomizados foi mais exacerbada do que nos animais controle ${ }^{8}$. Este trabalho sugere comportamento anômalo do epitélio cervical de ratas androgenizadas aos esteróides sexuais. Outro trabalho mostrou que o sistema imunológico local está alterado no colo uterino de ratas androgenizadas. De fato, há redução do número de células de Langerhans na mucosa desta região ${ }^{9}$.

Outros autores sugerem que os glicosaminoglicanos, principalmente a heparina do estroma cervical, seriam responsáveis pelo controle da proliferação epitelial, tanto do componente cilíndrico quanto do escamoso ${ }^{10,11}$. Além disto, os androgênios agiriam sobre a redução da produção de glicosaminoglicanos, principalmente heparina, além do que atuariam em fibroblastos e na resposta inflamatória local, bem como na proliferação epitelial $^{12,13}$. Estas alterações seriam permanentes em ratas androgenizadas no período neonatal, mesmo após a ovariectomia ${ }^{8}$. Por outro lado, a dexametasona reduziria a proliferação epitelial in vitro $^{14}$ e in vivo ${ }^{15}$. Além disto, os glicocorticóides também elevariam a produção de glicosaminoglicanos, principalmente do sulfato de heparina ${ }^{16}$. Assim, o objetivo deste trabalho é avaliar se a administração de dexametasona associada ao estrogênio reverteria as alterações da JEC causadas pela androgenização com o propionato de testosterona em ratas.

\section{Material e Métodos}

Foram utilizadas quarenta ratas albinas (Rattus norvegicus albinus, Rodentia, Mammalia), da linhagem OUTB EPM-1 Wistar, recém-nascidas. Os animais foram fornecidos pelo Centro de Desenvolvimento de Modelos Experimentais em Medicina e Biologia (CEDEME) da Universidade Federal de São Paulo / Escola Paulista de Medicina (UNIFESP/EPM).

Os animais recém-nascidos foram divididos em dois grupos: o controle, que recebeu apenas o veículo $(n=15)$, e o de estro permanente, que recebeu $1,25 \mathrm{mg} /$ animal de propionato de testosterona $(n=25)$, segundo a técnica preconizada por Barraclough (1961) ${ }^{17}$. Após 60 dias do tratamento, foram colhidos esfregaços vaginais, diariamente, por trinta dias consecutivos. Dos animais que receberam o veículo, dez tiveram ciclos regulares de quatro dias e foram incluídos nesse estudo. Já no grupo que foi androgenizado, quatro animais morreram durante o estudo e um não entrou em estro permanente (anovulação). Os animais restantes foram usados neste experimento.

Cinco animais do grupo controle e quinze das ratas em estro permanente foram submetidos a ovariectomia bilateral. Após trinta dias da ovariectomia (Ovx), todos os animais foram reagrupados em seis grupos, a saber: GEF - estro fisiológico sem castração $(n=5)$; GOVX - estro fisiológico com Ovx e tratados com propilenoglicol (veículo) (n=5); GEP - estro permanente (EP) sem castração (n=5); GEPOVX - em EP com Ovx e tratados com o veículo ( $n=5)$; GESTR - EP com Ovx e tratados com $10 \mathrm{mg} /$ dia de 3-benzoato de beta-estradiol, SC $(\mathrm{n}=5)$, e GDEXAR - EP com Ovx e tratados com 10 $\mathrm{mg} /$ dia de 3-benzoato de beta-estradiol e 0,8 mg/ dia de dexametasona, $\mathrm{SC}(\mathrm{n}=5)$. As substâncias utilizadas foram diluídas em propilenoglicol (veículo).

Após cinco dias de tratamento, todos os animais foram anestesiados, sacrificados e, rapidamente, o útero juntamente com a vagina foram removidos e fixados em líquido de Bouin. Após 24 horas de fixação, os fragmentos do colo uterino 
junto com a vagina foram incluídos em parafina para obtenção de cortes longitudinais de $3 \mu \mathrm{m}$ de espessura, paralelamente ao maior eixo do conjunto colo e vagina, para melhor avaliação da transição dos epitélios. A coloração foi feita pela técnica de hematoxilina e eosina (HE). A análise da JEC foi realizada em microscopia de luz.

A determinação do índice mitótico foi realizada contando-se o número de mitoses presentes em 1000 células de cada região estudada em cada animal. Desta maneira células foram analisadas, a partir da JEC, tanto para a região da ectocérvice quanto para a da endocérvice, em microscópio de luz com aumento de 800 vezes. $\mathrm{Na}$ região da ectocérvice foi analisada apenas a camada basal. A espessura dos epitélios foi avaliada com o auxílio de uma ocular de medição $(\mathrm{Kpl}$ - 8X da Zeiss) acoplada a microscópio de luz sob aumento de 800 vezes.

Para a análise dos resultados utilizou-se análise de variância (ANOVA) e, quando significante, complementou-se com o teste de comparações múltiplas de Bonferroni entre os grupos $(\alpha \leq 0,05)$.

\section{Resultados}

\section{Morfológicos}

GEF - A JEC apresenta epitélio cilíndrico simples, intensamente infiltrado por leucócitos no canal endocervical e epitélio estratificado pavimentoso não queratinizado do lado ectocervical (Figura 1A). Na região de contato entre esses dois tipos de epitélio, há avanço discreto do epitélio cilindrico sobre o escamoso para fora do canal endocervical, onde se observam figuras de mitose.

GOVX - Tanto o epitélio endocervical quanto o ectocervical são pouco desenvolvidos em relação ao GEF. O revestimento do canal endocervical está constituído por células cilíndricas que se continuam com o estratificado escamoso da ectocérvice. A lâmina própria é rica em fibras colágenas e há pouca infiltração leucocitária, e no tecido epitelial, raras figuras de mitose (Figura 1B).

GEP - O epitélio cilíndrico simples apresenta pouca infiltração leucocitária e na região de transição para o epitélio estratificado pavimentoso, que nesse grupo apresenta-se queratinizado, mostra-se bastante irregular (Figura 1C). Observamse, com certa freqüência, áreas de epitélio cilíndrico entremeadas ao estratificado e em alguns locais do epitélio cilíndrico observam-se brotos intra-epiteliais em direção à lâmina própria. A lâmina própria mostrou grande concentração de eosinófilos e raras glândulas endocervicais. Há também avanço acentuado do epitélio cilíndrico para a região cervical em contato com a vagina. Neste grupo notam-se inúmeras figuras de mitose.

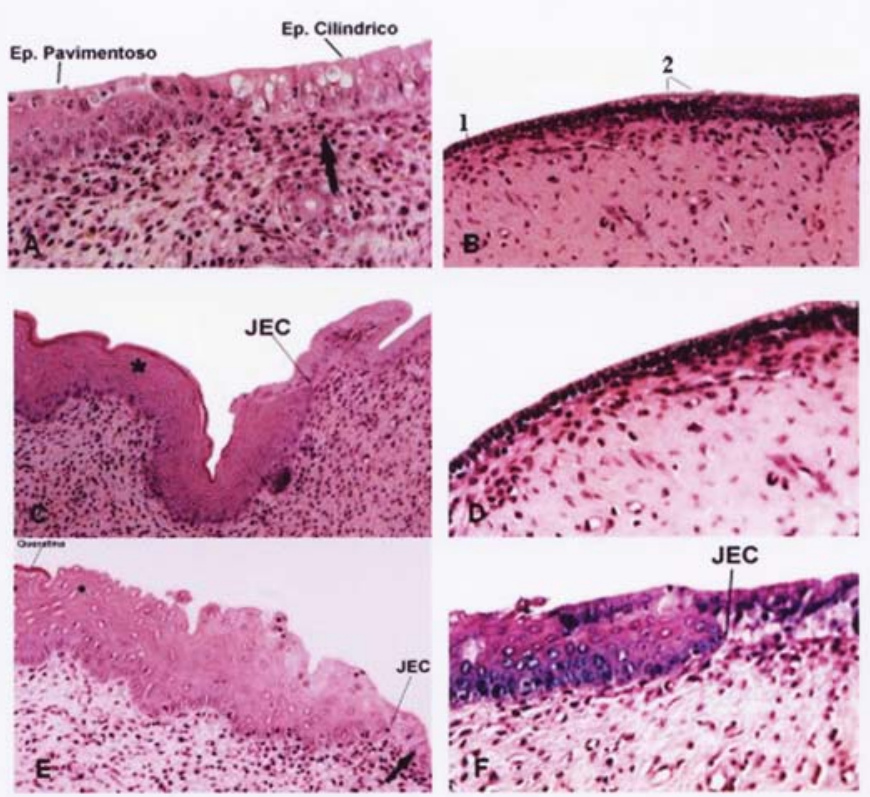

Figura 1 - Fotomicrografias mostrando cortes longitudinais da junção escamo-colunar (JEC) do colo uterino das ratas pertencentes aos vários grupos estudados. Em A (GEF), notar epitélio cilíndrico sobrepondo-se ao epitélio estratificado. Observar, na lâmina própria, leucócito (seta). Em B (GOVX) e D (GEPOVX), o epitélio cilíndrico simples (1) continua-se com o epitélio estratificado (2), sendo ambos atróficos. Em C (GEP), notamse JEC e epitélio estratificado pavimentoso queratinizado ( $\left.{ }^{*}\right)$. Em E (GESTR), a JEC (epitélio cilíndrico - seta) continua-se com o epitélio estratificado pavimentoso. Em $\mathrm{F}$ (GDEXAR), observa-se a junção escamo-colunar (JEC) após a administração de estrogênios conjugados e dexametasona, semelhante à do GEF. (HE 240X). GEF = estro fisiológico sem castração; GOVX = estro fisiológico com ovariectomia (OvX) e tratados com propilenoglicol; GEP = estro permanente (EP) sem castração; GEPOVX = em EP com Ovx e tratados com propilenoglicol; GESTR = EP com Ovx e tratados com $10 \mathrm{mg} / \mathrm{dia}$ de 3-benzoato de beta-estradiol; GDEXAR = EP com Ovx e tratados com $10 \mathrm{mg} / \mathrm{dia}$ de 3benzoato de beta-estradiol e $0,8 \mathrm{mg} / \mathrm{dia}$ de dexametasona.

GEPOVX - Nota-se epitélio endocervical, pouco desenvolvido, constituído por células cúbicas ou cilíndricas, continuando com um epitélio cúbico ou cilíndrico estratificado. A endocérvice está constituída por duas ou três camadas de células. A lâmina própria apresenta poucas glândulas endocervicais e grande concentração de fibras colágenas (Figura 1D).

GESTR - A JEC mostra-se irregular, sem limites precisos. A porção endocervical está revestida por epitélio cilíndrico simples bem desenvolvido, inclusive contendo locais com epitélio estratificado pavimentoso queratinizado e outros, não queratinizado, onde se pode observar elevado número de figuras de mitose. Além disto, o epitélio cilindrico invade e substitui partes do epitélio escamoso na ectocérvice. A lâmina própria mostrou grande concentração de eosinófilos e redução de glândulas endocervicais em relação ao GEF 
(Figura 1E). O aspecto da JEC deste grupo é muito semelhante ao GEP, com cornificação aumentada do epitélio escamoso e elevado número de mitoses.

GDEXAR - A JEC é bem delimitada e regular, com endocérvice revestida por epitélio cilíndrico simples e ectocérvice contendo epitélio estratificado pavimentoso não queratinizado. O aspecto da JEC é muito semelhante ao GEF (Figura 1F).

\section{Morfométricos}

Os dados morfométricos estão expressos na Tabela 1. Com relação ao índice mitótico observado na ectocérvice, os animais castrados sem tratamento hormonal (GOVX e GEPOVX) tiveram va- lores significantemente menores $(0,04)$ que os animais do GEF, GEP e GESTR $(0,36 ; 0,42$ e 0,45, respectivamente) (entre 0,24 e 0,60$)(p<0,05)$, com exceção do grupo GDEXAR. Além disso, o GESTR apresentou índices mitóticos superiores aos do GDEXAR $(p<0,05)$. Já na endocérvice dos animais castrados sem tratamento hormonal (GOVX e GEPOVX), o índice mitótico foi inferior ao dos GEF, GEP e GESTR ( $p<0,05)$, com exceção ao GDEXAR. Contudo, o GEF (estro fisiológico) não mostrou diferença significante em relação ao GDEXAR. Os resultados do GEP e GESTR foram muito maiores que o GDEXAR $(\mathrm{p}<0,05)$.

Tabela 1 - Resultados da determinação do índice mitótico, da espessura do epitélio e do número de glândulas da junção escamo-colunar das ratas nos vários grupos de estudo (média \pm erro padrão da média).

\begin{tabular}{|c|c|c|c|c|c|c|}
\hline \multirow[b]{2}{*}{ Estrutura analisada } & \multicolumn{6}{|c|}{ Grupos de estudo } \\
\hline & GEF & GOVX & GEP & GEPOVX & GESTR & GDEXAR \\
\hline Índice mitótico na ectocérvice & $0,36 \pm 0,03 a$ & $0,04 \pm 0,01^{c}$ & $0,42 \pm 0,08 \mathrm{a}^{\mathrm{a}}$ & $0,04 \pm 0,02 c$ & $0,45 \pm 0,12^{a}$ & $0,14 \pm 0,02$ \\
\hline Índice mitótico na endocérvice & $0,24 \pm 0,01 b$ & $0,01 \pm 0,02 c$ & $0,60 \pm 0,03{ }^{a}$ & $0,01 \pm 0,01^{c}$ & $0,60 \pm 0,10$ a & $0,08 \pm 0,01$ \\
\hline Número de glândulas endocervicais & $10,5 \pm 0,8^{b}$ & $5,5 \pm 0,6^{b}$ & $19,9 \pm 1,3^{a}$ & $6,7 \pm 1,4^{b}$ & $17,3 \pm 1,2^{a}$ & $7,3 \pm 1,1^{b}$ \\
\hline Espessura do epitélio endocervical ( $\mu \mathrm{m})$ & $37,0 \pm 1,2^{b}$ & $10,0 \pm 1,5^{c}$ & $64,0 \pm 3,5^{a}$ & $10,9 \pm 0,2^{c}$ & $63,5 \pm 12,5^{a}$ & $14,5 \pm 4,5^{c}$ \\
\hline Espessura do epitélio ectocervical $(\mu \mathrm{m})$ & $147,2 \pm 32,8$ & $68,1 \pm 22,5$ & $152,1 \pm 42,2$ & $57,0 \pm 33,4$ & $172,5 \pm 42,5$ & $138,2 \pm 22,5$ \\
\hline
\end{tabular}

Índice mitótico na ectocérvice: GEF, GEP, GESTR > GDEXAR > GOVX, GEPOVX $(p<0,05)$. Índice mitótico na endocérvice: GEP, GESTR > GEF > GOVX, GEPOVX, GDEXAR $(p<0,05)$.

Número de glândulas endocervicais: GEP, GESTR > GEF, GOVX, GEPOVX e GDEXAR $(p<0,05)$.

Espessura do epitélio endocervical: GEP, GESTR > GEF > GOVX, GEPOVX, GDEXAR $(p<0,05)$

$a>b>c$. Para a abreviação dos grupos, ver legenda da Figura 1.

Após a análise das glândulas endocervicais, os animais do GEP e GESTR mostraram maior número de glândulas $(19,9$ e 17,3$)$ que os outros grupos (GEF, GOVX, GEPOVX e GDEXAR) (5,5 a 10,5). Já a espessura do epitélio endocervical do GEF foi maior que dos grupos GOVX e GEPOVX $(p<0,05)$ e inferior a dos GEP e GESTR $(p<0,05)$. Já os animais do GEP e GESTR tiveram maior espessura epitelial do que os outros grupos (GEF, GOVX, GEPOVX e GDEXAR, $p<0,05)$.

Não houve diferenças significantes quanto à espessura do epitélio ectocervical entre os vários grupos $(p>0,05)$, mas houve tendência de diminuição nos animais castrados sem reposição hormonal comparados aos outros grupos.

\section{Discussão}

A administração de $1,25 \mathrm{mg}$ de propionato de testosterona em ratas recém-nascidas pode levar a alterações irreversiveis no hipotálamo. Nesses animais, há aumento da expressão do neuropeptídeo Y e diminuição da expressão do receptor de estrogênio e da liberação de GnRH pela eminência média e núcleo arqueado do hipotálamo ${ }^{18}$. Na idade adulta, essas ratas irão apresentar liberação anômala das gonadotrofinas e alteração da função ovariana e da ovulação. Conseqüentemente, os esfregaços vaginais irão refletir o distúrbio hormonal ovariano, pela permanência de maior porcentagem de células intermediárias, superficiais e cornificadas ${ }^{17}$.

Este modelo é usado para estudar anovulação crônica e até falência ovariana prematura ${ }^{19}$. Entretanto, outros estudos mostraram que a administração de androgênios no período neonatal leva a alterações cérvico-vaginais ${ }^{20}$. Essas alterações também ocorrem em outros animais, como em novilhos ${ }^{21}$. Além disto, há relatos de que a administração por longo prazo de androgênios em mulheres normais pode alterar o colo uterino, levando ao adelgaçamento epitelial ${ }^{2}$. Contudo, esta mudança é diferente da encontrada em nosso estudo em ratas imaturas.

No nosso estudo, as transformações do efeito do tratamento androgênico na JEC persistiram 
nas ratas ooforectomizadas e tratadas com estrogênio. Este efeito é oposto em ratas normais e não androgenizadas (dado não apresentado nos resultados). Já o tratamento com a dexametasona tornou a JEC mais regular e semelhante ao grupo controle com ciclo estral regular. Este dado sugere que os glicocorticóides seriam importantes para antepor-se à resposta exagerada de proliferação epitelial ao estrogênio em ratas previamente androgenizadas, inclusive se aproximando do aspecto dos animais em estro fisiológico. Os dados morfométricos suportam estas hipóteses.

Uma explicação para aquele fato seria ação direta da dexametasona nas células epiteliais da JEC. Deve-se ressaltar que alguns experimentos mostraram que este hormônio atua na redução do indice de mitoses ${ }^{22}$, da replicação e da sintese de DNA das células epiteliais ${ }^{23}$. Outra explicação seria a ação da dexametasona sobre o aumento da produção de glicosaminoglicanas, principalmente sobre o heparan sulfato no estroma cervical ${ }^{16}$. No endotélio vascular, esta substância diminui a ação do fator de crescimento fibroblástico ${ }^{24}$. Em coelhos, o heparan sulfato é importante para maturação do epitélio cervical ${ }^{25} \mathrm{e}$, em mulheres, há evidências de sua ação na proliferação do epitélio cervical ${ }^{26}$. Deve-se ainda reforçar que fatores de crescimento são mais importantes para expressão desta glicosaminoglicana do que a ação direta de estrogênio e progesterona ${ }^{26}$.

Apesar de alguns autores mostrarem o efeito dos glicocorticóides no sistema reprodutor feminino ${ }^{27}$ e apesar também dos resultados deste trabalho, os mecanismos de ação destes hormônios ainda não estão totalmente elucidados. Contudo, os nossos resultados sugerem que os glicocorticóides, em especial a dexametasona, seriam importantes para restabelecer a normalidade da JEC em ratas previamente androgenizadas.

\section{ABSTRACT}

Purpose: to evaluate the effects of estradiol benzoate associated with dexamethasone on the squamocolumnar junction (SCJ) of rats in permanent estrus (PE) and then ovariectomized (Ovx).

Methods: thirty female rats were divided into six groups of five animals each: PhEG -rats in physiological estrus (PhE) treated with propylene glycol (vehicle); OVXG-rats in PhE, $O v x$ and treated with vehicle; $P E G$ - rats in PE treated with vehicle; $P E O V X G$-rats in $P E$, Ovx and treated with vehicle; ESTRG-rats in PE, Ovx and treated with $10 \mathrm{mg}$ per day benzoate of estradiol, and DEXAG-in PE, Ovx and treated with $10 \mathrm{mg}$ per day estradiol benzoate associated with 0.8 $m g$ dexamethasone. PE induction was performed with 1.25 mg testosterone propionate per animal per day after birth. After 90 days, rats in the OVXG, EPOVXG, ESTRG, and DEXAG groups were ovariectomized. After 21 days of castration, all animals received the corresponding treatment for five days. At the end of the experiment, all animals were sacrificed and the uteri removed for histological routine.

Results: the borders of the SCJ in the PEG were irregular and not clearly delineated, with many buds towards the direction of the lamina propria as well as a reduction in the leukocyte number compared to the PhEG. The SCJ of the OVXG and PEOVXG was not very visible, with cubical epithelium on the endometrial side and with reduction in the layers of squamous epithelium due to stromal atrophy. The $S C J$ in the ESTRG was more developed than in the OVXG and PEOVXG, but it was similar to that of the PEG, having unclear borders. In contrast, the SCJ of the DEXAG was welldelineated and similar to the PhEG.

Conclusion: our data suggest that estrogen associated with dexamethasone may be important for remodeling SCJ morphology in female rats with previously induced permanent estrus and subsequent ovariectomy.

KEYWORDS: Cervical histology. Squamocolumnar junction. Estrogen.

\section{Referências}

1. Pérez JLL, Rodríguez SPG. Fisiología feminina II: Ciclo uterino. Ciclo endometrial. Ciclo miometrial. Menstruación. Ciclo endocervical. Procesos preparattivos cervicales. Ciclo y fisiología de la vagina y la vulva. In: Cabero Roura L, editor. Tratado de Ginecología, Obstetricia y Medicina de la Reproducción. $1^{a}$ ed. Madrid: Panamericana; 2003; 94-102.

2. Miller N, Bedard YC, Cooter NB, Shaul DL. Histological changes in the genital tract in transsexual women following androgen therapy. Histopathology 1986; 10:661-9.

3. Megevand E, Denny LA, Soeters R, Nevin J, Dehaeck $\mathrm{K}$, Bloch B. The influence of hormonal status on excision margins after large loop excision of the transformation zone (LLETZ). Eur J Gynaecol Oncol 1996; 17:223-7.

4. Kaushic C, Zhou F, Murdin AD, Wira CR. Effects of estradiol and progesterone on susceptibility and early immune responses to Chlamydia trachomatis infection in the female reproductive tract. Infect Immun 2000; 68:4207-16.

5. Datta IC, Karkun JN, Kar AB. Studies on physiology and biochemistry of the cervix. Effect of estrogen and progesterone on the rat cervix. Acta Biol Med Germ 1968; 20:155-62. 
6. Valente CA, Sasso WS. Morphology and morphometry of the cervix uteri of female albino rats in the estrus and diestrus phases. Rev Bras Biol 1992; 52:527-32.

7. Ramos JG, Varayoud J, Bosquiazzo VL, Luque EH, Munoz-de-Toro M. Cellular turnover in the rat uterine cervix and its relationship to estrogen and progesterone receptor dynamics. Biol Reprod 2002; 67:735-42.

8. Ohta Y, Iguchi T. Effects of progesterone plus estradiol on vaginal epithelium showing estrogen-independent proliferation and cornification in neonatally estrogenized and androgenized mice. Proc Jpn Acad 1976; 52:583-6.

9. Bykov VL. Langerhans cells of the mucous membranes of the digestive and reproductive tracts in laboratory mice and rats. Morfologiia 1997; 112:73-7.

10.Wright TC Jr, Johnstone TV, Castellot JJ, Karnovsky MJ. Inhibition of rat cervical epithelial cell growth by heparin and its reversal by EGF. J Cell Physiol 1985; 125:499-506.

11.Wright TC Jr, Karnovsky MJ. Metabolic effects of heparin on rat cervical epithelial cells. J Cell Physiol 1987; 132:255-62.

12.Steward A, Bayley DL. Effects of androgens in models of rheumatoid arthritis. Agents Actions 1992; 35:268-72.

13.Xie MH, Holcomb I, Deuel B, et al. FGF-19, a novel fibroblast growth factor with unique specificity for FGFR4. Cytokine 1999; 11:729-35.

14.Cariou R, Harousseau JL, Tobelem G. Inhibition of human endothelial cell proliferation by heparin and steroids. Cell Biol Int Rep 1988; 12:1037-47.

15.Ohta Y, Takanosawa M, Matumoto C, Makino N, Ishimoto S, Ichimura K. High-dose glucocorticoids inhibit proliferation of rat olfactory epithelium. Ann Otol Rhinol Laryngol 2002; 111:909-11.

16.Kasinath BS, Singh AK, Kanwar YS, Lewis EJ. Dexamethasone increases heparan sulfate proteoglycan core protein content of glomerular epithelial cells. J Lab Clin Med 1990; 115:196-202.
17.Barraclough CA. Production of anovulatory, sterile rats by single injections of testosterone propionate. Endocrinology 1961; 68:62-7.

18.Sun F, Yu J, Zhang L. Effect of tiangui recipe on expressions of hypothalamic leptin receptor and messenger ribonucleic acid of neuropeptide $\mathrm{Y}$ in androgen-sterilized rats. Zhongguo Zhong Xi Yi Jie He Za Zhi 2000; 20:362-4.

19.Bukovsky A, Ayala ME, Dominguez R, et al. Postnatal androgenization induces premature aging of rat ovaries. Steroids 2000; 65:190-205.

20.Bern HA, Mills KT, Mori T. Effects of long-term implantation of vaginal concretions on the cervicovaginal epithelium of mice. Proc Soc Exp Biol Med 1984; 177:303-7.

21.Groot MJ, den Hartog JM, Gruys E. Influence of androgens on the genital tract of cyclic heifers. Vet Q 1989; 11:198-209.

22.Gunin AG, Mashin IN, Zakharov DA. Proliferation, mitosis orientation and morphogenetic changes in the uterus of mice following chronic treatment with both estrogen and glucocorticoid hormones. J Endocrinol 2001; 169:23-31.

23.Bigsby RM. Progesterone and dexamethasone inhibition of estrogen-induced synthesis of DNA and complement in rat uterine epithelium: effects of antiprogesterone compounds. J Steroid Biochem Mol Biol 1993; 45:295-301.

24.Forsten KE, Courant NA, Nugent MA. Endothelial proteoglycans inhibit bFGF binding and mitogenesis. J Cell Physiol 1997; 172:209-20.

25.Belayet HM, Kanayama N, Khatun S, Sumimoto K, Kobayashi T, Terao T. Binding of interleukin-8 to heparan sulphate enhances cervical maturation in rabbits. Mol Hum Reprod 1999; 5:261-9.

26.Inki P. Expression of syndecan-1 in female reproductive tract tissues and cultured keratinocytes. Mol Hum Reprod 1997; 3:299-305.

27.Vital Reyes VS, Tellez Velasco S, Hinojosa Cruz JC, Reyes Fuentes A. Clomiphene acetate and prednisone: alternative approach for the management of patients with chronic anovulation and clomiphene treatment failure. Ginecol Obstet Mex 2000; 68:266-70. 